\title{
The number of loci controlling the sporophytic self-incompatibility system in Sinapis arvensis L.
}

\author{
J. P. Stevens and \\ Q. O. N. Kay
}

School of Biological Sciences, University College of Swansea, Singleton Park, Swansea, SA2 8PP, U.K.

A breeding programme designed to establish the number of loci controlling the sporophytic self-incompatibility system in Sinapis arvensis has been completed. The programme involved analyses of diallel crosses within $F_{1}$ and $F_{2}$ families derived from crosses between plants from geographically remote populations, and within self families derived from the parental plants. Incompatibility reactions were determined cytologically using fluorescence microscopy. Control by a single locus has been established. However, the expression of individual S-alleles may be modified, as shown by incomplete dominance in a self family, and mutual weakening in an $F_{1}$ family.

\section{INTRODUCTION}

Sinapis arvensis is a common, widespread annual of cultivated ground. It is a diploid member of the Brassicaceae, and has a system of self-incompatibility in which the mating-type of the pollen grain is determined by the sporophyte, the incompatibility reaction occurs on the stigma surface, and dominance interactions occur between some of the many S-alleles (Ford and Kay, 1985). This type of self-incompatibility was first described in the Asteraceae by Gerstel (1950) and Hughes and Babcock (1950), and then shortly afterwards in the Brassicaceae by Bateman (1954). Since then, similar sporophytic multi-allelic systems have been found to operate in every self-incompatible species investigated from these two families.

Unlike gametophytic self-incompatibility systems, in which examples of single, bi- and multilocus control are well substantiated (e.g., Lawrence et al., 1978; Cornish et al., 1979; Østerbye, 1986; respectively), all genetic studies of self-incompatibility with diploid Asteraceae (Gerstel, 1950; Hughes and Babcock, 1950; Crowe, 1954; Imrie and Knowles, 1971; Eenink, 1981; Stephens, et al., 1982), and the majority of studies with diploid Brassicaceae (Bateman, 1954, 1955; Sampson, 1957a, b, 1958, 1964; Thompson, 1957; Lloyd, 1967; Richards and Thurling, 1973; Mackay, 1977; Zuberi et al., 1981) are consistent with single locus control. The main exception is the study of Eruca sativa (Brassicaceae) by Verma et al. (1977) in which at least three S-loci were implicated. Additionally, the number of S-loci has been disputed in Raphanus sativus (Sampson, 1957b; Lewis, 1979) and $R$. raphanistrum (see Sampson, 1964).

The results from preliminary work on the genetics of incompatibility in S. arvensis (Ford and Kay, 1985; Ford, 1986) were consistent with single locus control, because a maximum of three incompatibility groups segregated in the self families of the plants studied. However, the possibility of additional S-loci could not be entirely ruled out, because self families from only a relatively small sample of plants (10) from a single natural population were studied, and because a complete diallel cross was not performed for any one self family. In the light of the suggestion by Verma et al. (1977) and Lewis $(1977,1979)$ that sporophytic selfincompatibility in the Brassicaceae is, in at least some species, controlled by more than one locus, it was important to carry out a more definitive test of the monofactorial hypothesis of control in $S$. arvensis as a prerequisite to further studies on the population genetics of the self-incompatibility polymorphism in this species.

\section{MATERIALS AND METHODS}

The number of incompatibility groups was determined in an $F_{1}$ and an $F_{2}$ generation family descended from each of two crosses between plants from 
geographically remote, natural populations: cross $1=\mathrm{KX} 17$ (Crete) $\times \operatorname{LS12}$ (Lincolnshire), cross $2=$ KX13 (Crete) $\times$ WF184 (South Wales). In addition, the number of incompatibility groups segregating in a self family from each of the four parental plants was determined. The $F_{1}$ and $F_{2}$ families consisted of 20-21 plants, and the self families of 10 plants; each family was analysed by an intra-family diallel cross.

WF184 and LS12 were raised from seed collected by M. A. Ford from a population at Windmill Farm, Gower, South Wales (G.R. SS 474.925) and a population near Little Steeping, Lincolnshire (G.R. TF 440.609) respectively. KX13 and KX17 were raised from seed collected by us from a population near Koxares, Crete. All three populations were large, and situated around the borders of arable fields.

The crossing programme was carried out in 1986 and 1987 in an insect-proof greenhouse with supplementary lighting and heating to give a 16hour day and to maintain a minimum temperature of $16^{\circ} \mathrm{C}$ in the winter months. Compatibility reactions were determined cytologically by scoring pollen tube penetration of the stigma and style, using the well-documented and reliable technique of staining mascerated pistils in aniline blue and examining under a fluorescence microscope (Kho and Baër, 1968; Wallace, 1979b). Each cross was repeated on two or three stigmas which were liberally coated with pollen from freshly dehisced anthers held by their filaments in a pair of alcoholwashed, watchmaker's forceps. Self seeds, and seeds from incompatible crosses, were obtained by bud-pollination. Individual $\mathrm{S}$-alleles were identified by test-crossing with plants of known incompatibility genotype, raised from a seed collection of $S$. arvensis.

\section{RESULTS AND CONCLUSIONS}

\section{Parental plants}

The four parental plants were all fully self-incompatible, and reciprocally cross-compatible.

\section{Self families}

Three incompatibility groups segregated in three of the four self families; in the remaining family, all crosses were reciprocally incompatible, i.e., only one incompatibility group occurred (fig. 1).

Consider first the three segregating families. In each family, two groups, which both occurred at a low frequency, were reciprocally compatible; these groups do not therefore share an expressed $\mathrm{S}$-allele. The third group, present in greater numbers, was reciprocally incompatible with both low frequency groups in two families (KX17 and WF184), and showed a reciprocal difference with one of these groups in the other family (KX13) (fig. 1). This indicates that the third group has an S-allele in common with both the low frequency groups. These results are consistent with segregation at a single heterozygous S-locus: the two low frequency, reciprocally compatible groups represent the two S-allele homozygotes, while the third, more frequent group is the S-allele heterozygote. When the heterozygote is reciprocally incompatible with both homozygotes, the S-alleles are co-dominant (i.e., both are fully expressed in the heterozygote), while dominance of one S-allele in either pollen or stigma, with co-dominance in the other organ, causes a reciprocal difference between the heterozygote and the recessive homozygote. In the KX13 self family, the compatible pollinations occur when the heterozygote (group C) is the female parent, so dominance occurs in the stigma and co-dominance in the pollen. The frequencies of the incompatibility groups in each family can be tested for goodness-of-fit to a 1:2:1 ratio, which is expected following segregation at a single $\mathrm{S}$ locus, by using chi-square. However, in a family of size 10 , the expected number of each homozygote is small $(2 \cdot 5)$. Therefore the two homozygous classes were pooled within each family. The resulting frequencies were not significantly different from $1: 1$ ratios $\left(\mathrm{KX17}, \chi_{(1)}^{2}=1 \cdot 6, P>0 \cdot 1\right.$; $\mathrm{KX} 13, \chi_{(1)}^{2}=0.0$; WF184, $\left.\chi_{(1)}^{2}=0.4, P>0.5\right)$.

Consider now the non-segregating family (LS12, fig. 1). The probability that a self family of size 10 , segregating at a single S-locus, will contain both homozygotes can be calculated as 0.89 (see Mackay, 1977). Correspondingly, the probability that four self families of size 10 will all contain both homozygotes is $0 \cdot 89^{4}=0 \cdot 63$. Therefore, there is a fairly high probability $(1-0.63=0.37)$ that one of the four self families examined would not contain both homozygotes. This is one explanation for the self family in which only one incompatibility group occurred. An alternative explanation is that the parental plant was homozygous at the S-locus. With sporophytic control of self-incompatibility, homozygotes for common, recessive Salleles can occur, and have been observed in two cultivated varieties of Brassica oleracea (Ockendon and Currah, 1979; Ockendon, 1980), although not, to our knowledge, in any wild species. In order to distinguish between these two possibilities, it was of interest to analyse more plants from the LS12 
self family, which in fact consisted of a total of 23 plants from which a random 10 had been selected for use in the diallel. Chains of cross-pollinations were made, linking plants used in the diallel with the remaining 13 . A reciprocally compatible cross was soon found, which indicated that the family was segregating, the two plants involved being the two different homozygotes. All the other plants in the family were subsequently crossed with the two homozygotes in order to identify the incompatibility group of every plant, and to determine the dominance relationships of the S-alleles. The 23 plants were found to consist of 14 heterozygotes, in which the S-alleles were co-dominant in both pollen and stigma, 7 of one homozygote and 2 of the other homozygote. This ratio is not significantly different from a $1: 2: 1$ ratio $\left(\chi_{(2)}^{2}=3 \cdot 26, P>0 \cdot 1\right)$.
Test-crossing the two homozygotes from each family with plants of known S-allele genotype revealed that the identities of the $\mathrm{S}$-alleles were as follows: $\quad \mathrm{KX} 17=\mathrm{S}_{20.36} ; \mathrm{LS12}=\mathrm{S}_{32.38} ; \quad \mathrm{KX} 13=$ $\mathrm{S}_{20 \cdot 37} ; \mathrm{WF} 184=\mathrm{S}_{13 \cdot 23}$. In KX13, the stigma recessive allele is $\mathrm{S}_{20}$. Some degree of "leakiness" of the incompatibility reaction was observed in the self family of WF184, notably following crosses of the type $S_{23.23} \times S_{13.23}$ and $S_{13.23} \times S_{13.13}$ (fig. 1). That these crosses represent leaky incompatible reactions was clear from the cytological observations; typically only one or two of the three pistils scored per cross contained pollen tubes, and in these pistils only a few pollen tubes penetrated the style. It would appear that $S_{13}$ is incompletely dominant in the pollen, and $S_{23}$ incompletely dominant in the stigma.
KX17

\begin{tabular}{|r|c|cc|ccccccc|}
\hline \multirow{2}{*}{8} & A & \multicolumn{2}{|c|}{ B } & \multicolumn{7}{|c|}{ C } \\
\cline { 2 - 10 } & I & 2 & 3 & 4 & 5 & 6 & 7 & 8 & 9 & 10 \\
\hline 1 & & C & C & I & I & I & I & I & I & I \\
\hline 2 & C & & I & I & I & I & I & I & I & I \\
3 & C & I & & I & I & I & I & I & I & I \\
\hline 4 & I & I & I & & I & I & I & I & I & I \\
5 & I & I & I & I & & I & I & I & I & I \\
6 & I & I & I & I & I & & I & I & I & I \\
7 & I & I & I & I & I & I & & I & I & I \\
8 & I & I & I & I & I & I & I & & I & I \\
9 & I & I & I & I & I & I & I & I & & I \\
10 & I & I & I & I & I & I & I & I & I & \\
\hline
\end{tabular}

KX13

\begin{tabular}{|r|cc|ccc|ccccc|}
\hline \multirow{2}{*}{8} & \multicolumn{2}{|c|}{ A } & \multicolumn{3}{|c|}{ B } & \multicolumn{5}{|c|}{ C } \\
\cline { 2 - 10 } & 1 & 2 & 3 & 4 & 5 & 6 & 7 & 8 & 9 & 10 \\
\hline 1 & & I & C & C & C & C & C & C & C & C \\
2 & I & & C & C & C & C & C & C & C & C \\
\hline 3 & C & C & & I & I & I & I & I & I & I \\
4 & C & C & I & & I & I & I & I & I & I \\
5 & C & C & I & I & & I & I & I & I & I \\
\hline 6 & I & I & I & I & I & & I & I & I & I \\
7 & I & I & I & I & I & I & & I & I & I \\
8 & I & I & I & I & I & I & I & & I & I \\
9 & I & I & I & I & I & I & I & I & & I \\
10 & I & I & I & I & I & I & I & I & I & \\
\hline
\end{tabular}

LS12

\begin{tabular}{|c|c|c|c|c|c|c|c|c|c|c|}
\hline$q$ & \multicolumn{10}{|c|}{ A } \\
\hline $0^{0}$ & 1 & 2 & 3 & 4 & 5 & 6 & 7 & 8 & 9 & 10 \\
\hline 1 & & I & I & I & I & I & I & I & I & I \\
\hline 2 & I & & I & I & I & I & I & I & I & I \\
\hline 3 & I & I & & I & I & I & I & I & I & I \\
\hline 4 & I & I & I & & I & I & I & I & I & I \\
\hline 5 & I & I & 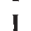 & I & & I & I & I & I & I \\
\hline 6 & I & I & I & I & I & & I & I & I & I \\
\hline 7 & I & I & I & I & I & I & & I & I & I \\
\hline 8 & I & I & I & I & I & I & I & & I & I \\
\hline 9 & I & I & I & I & I & I & I & I & & I \\
\hline 10 & I & I & I & I & I & I & I & I & I & \\
\hline
\end{tabular}

Figure 1 Results of the diallel crosses for the self families of the four parental plants: KX17, LS12, KX13 and WF184 respectively. $\mathrm{C}=$ compatible, $\mathrm{I}=$ incompatible, $\mathrm{I}^{*}=$ leaky incompatible (see text). The S-allele genotypes of the incompatibility groups in family $\mathrm{KX17}$ are $\mathrm{A}=\mathrm{S}_{20 \cdot 20}, \mathrm{~B}=\mathrm{S}_{36 \cdot 36}, \mathrm{C}=\mathrm{S}_{20 \cdot 36}$; in family $\mathrm{KX13}, \mathrm{A}=\mathrm{S}_{20 \cdot 20}, \mathrm{~B}=\mathrm{S}_{37 \cdot 37}, \mathrm{C}=\mathrm{S}_{20 \cdot 37}$; in family WF184, $\mathrm{A}=$ $\mathrm{S}_{23 \cdot 23}, \mathrm{~B}=\mathrm{S}_{13 \cdot 13}, \mathrm{C}=\mathrm{S}_{23 \cdot 13}$. The plants in family LS12 consist of $3 \mathrm{~S}_{32 \cdot 32}$ and $7 \mathrm{~S}_{32 \cdot 38}$. 
Segregation at two heterozygous S-loci would have resulted in four to nine incompatibility groups in the self families, the exact number depending on the dominance relationships of the S-alleles. This hypothesis can, therefore, be ruled out. However, the possibility remains that the parental plants may be homozygous at a second polymorphic S-locus.

\section{$F_{1}$ generation}

Four incompatibility groups segregated in both $F_{1}$ families in frequencies not significantly different from $1: 1: 1: 1$ ratios (cross $1, \chi_{(3)}^{2}=5 \cdot 48, P>0 \cdot 1$; cross $\left.2, \chi_{(3)}^{2}=2 \cdot 8, P>0 \cdot 25\right)$ (fig. 2). These results are consistent with monofactorial control, but again they do not enable us to rule out control by two complementary S-loci, because a cross of the type $S_{1 \cdot 2} Z_{1 \cdot 1} \times S_{3.4} Z_{2 \cdot 2}$ would also result in four incompatibility groups in a 1:1:1:1 ratio in the $F_{1}$.

Every plant is self-incompatible in the $F_{1}$ family from cross 1 , and there is co-dominance of the alleles in both pollen and stigma in each incompatibility group. In the $F_{1}$ family of cross 2 , one of the alleles in groups $B$ and $D\left(S_{20}\right)$ is recessive in the pollen, or in the stigma, or in both organs. Which of these three alternatives is the case in group D is unknown, but in group $B$, the $F_{2}$ generation results indicate that $S_{20}$ is recessive to $S_{23}$ in the stigma alone.

Leakiness of the incompatibility reaction was observed in some plants in the $F_{1}$ family of cross 2. Three of the seven plants in group $D\left(S_{13 \cdot 20}\right)$ were partially self-compatible. Partially compatible reactions also occurred in 23 of the 42 crosspollinations ( 55 per cent) between plants within group $\mathrm{D}$, and 22 of the 35 cross-pollinations (63 per cent) between plants from groups $C\left(S_{13.37}\right)$ and $\mathrm{D}$ when the group $\mathrm{D}$ plant was the female parent (fig. 2). These leaky incompatible reactions would appear to be caused by a weakening of the expression of $\mathrm{S}_{13}$ in the stigmas of group D plants.

\section{$F_{2}$ generation}

$\mathrm{F}_{2}$ families were raised from seeds obtained by crossing between two plants from group $\mathrm{C}$ of the $F_{1}$ family from cross 1 , and between two plants from group $B$ of the $F_{1}$ family from cross 2 .

Initially, pollinations within the $\mathrm{F}_{2}$ diallels were made reciprocally. However, once it became apparent that both families were segregating into three incompatibility groups, rather than four to nine as expected with the bifactorial model, the remaining crosses were made in one direction only.
In both families, the results from all unidirectional crosses fitted into one or other of the three incompatibility groups, so the reciprocal pollinations were not carried out.

In both families, the segregation ratio of the incompatibility groups fits the $1: 2: 1$ ratio expected on the basis of the one-locus model $\left(\operatorname{cross} 1, \chi_{(2)}^{2}=\right.$ $3.6, P>0 \cdot 1$; cross $2, \chi_{(2)}^{2}=0.4, P>0.75$ ) (fig. 3 ). In the $F_{2}$ family of cross 1 , the only compatible pollinations are those between the two different homozygotes. This confirms our conclusion from the $F_{1}$ diallel that $S_{20}$ and $S_{38}$ are co-dominant in pollen and stigma. In the $F_{2}$ family of cross 2 , the two homozygotes are again reciprocally compatible, but in addition, the heterozygote shows a reciprocal difference when crossed with homozygote $\mathrm{A}\left(\mathrm{S}_{20 \cdot 20}\right)$ (fig. 3). Since the compatible pollinations occur when the heterozygote is the female parent, $S_{20}$ must be recessive to $S_{23}$ in the stigma.

\section{DISCUSSION}

The four parental plants used in this study were each heterozygous at a single S-locus, as evidenced by the segregation of three incompatibility groups in their self families. The possibility remained that they were homozygous at a putative second locus. This situation could plausibly have arisen if ancestral populations carried two polymorphic S-loci and different $\mathrm{S}$-alleles became fixed at the second locus in geographically isolated localities. However, this possibility was eliminated by the segregation of only three incompatibility groups in the $F_{2}$ families. The parental plants could, of course, have been homozygous for the same Sallele at a second polymorphic locus, but this possibility is highly unlikely considering their remote geographic origins, from Crete, Lincolnshire and South Wales. In conclusion, despite the extensive analyses carried out, no evidence for the involvement of a second S-locus in the control of selfincompatibility in $S$. arvensis has been found.

The results from the majority of investigations into the genetics of self-incompatibility in the Brassicaceae are consistent with single locus control. The data from E. sativa of Verma et al. (1977) (discussed by Lewis, 1977) constitute the main exception since they require a minimum of three $\mathrm{S}$-loci to interpret. However, in this study, compatibility reactions were determined primarily by postfertilization development of the ovary, a method that may not allow a reliable distinction to be made between genuinely compatible and leaky incompatible reactions, both of which result in seed set. 
Cross 1

\begin{tabular}{|c|c|c|c|c|c|c|c|c|c|c|c|c|c|c|c|c|c|c|c|c|c|}
\hline \multirow{2}{*}{0} & \multicolumn{5}{|c|}{ A } & \multicolumn{7}{|c|}{ B } & \multicolumn{8}{|c|}{ C } & D \\
\hline & 1 & 2 & 3 & 4 & 5 & 6 & 7 & 8 & 9 & 10 & 11 & 12 & 13 & 14 & 15 & 16 & 17 & 18 & 19 & 20 & 21 \\
\hline 1 & I & I & I & I & I & I & I & I & I & I & I & I & I & I & I & I & I & I & I & I & C \\
\hline 2 & I & I & I & I & I & I & I & I & I & I & I & I & I & I & I & I & I & I & I & I & C \\
\hline 3 & I & I & I & I & I & I & I & I & I & I & I & I & I & I & I & I & I & I & I & I & C \\
\hline 4 & I & I & I & I & I & I & I & I & I & I & I & I & I & I & I & I & I & I & I & I & C \\
\hline 5 & I & I & I & I & I & I & I & I & I & I & I & I & I & I & I & I & I & I & I & I & C \\
\hline 6 & I & I & I & I & I & I & I & I & I & I & I & I & C & C & C & C & C & C & C & C & I \\
\hline 7 & I & I & I & I & I & I & I & I & I & I & I & I & C & C & C & C & C & C & C & C & I \\
\hline 8 & I & I & I & I & I & I & I & I & I & I & I & I & C & C & C & C & C & C & C & C & I \\
\hline 9 & I & I & I & I & I & I & I & I & I & I & I & I & C & C & C & C & C & C & C & C & I \\
\hline 10 & I & I & I & I & I & I & I & I & I & I & I & I & C & C & C & C & C & C & C & C & I \\
\hline 11 & I & I & I & I & I & I & I & I & I & I & I & I & C & C & C & C & C & C & C & C & I \\
\hline 12 & I & I & I & I & I & I & I & I & I & I & I & I & C & C & C & C & C & C & C & C & I \\
\hline 13 & I & I & I & I & I & C & C & C & C & C & C & $\mathrm{C}$ & I & I & I & I & I & I & I & I & I \\
\hline 14 & I & I & I & I & I & C & C & C & C & C & C & C & I & I & I & I & I & I & I & I & I \\
\hline 15 & I & I & I & I & I & C & C & C & C & C & C & C & I & I & I & I & I & I & I & I & I \\
\hline 16 & I & I & I & I & I & C & C & C & C & C & C & C & I & I & I & I & I & I & I & I & I \\
\hline 17 & I & I & I & I & I & C & C & C & C & C & C & C & I & I & I & I & I & I & I & I & I \\
\hline 18 & I & I & I & I & I & C & C & C & C & C & C & C & I & I & I & I & I & I & I & I & I \\
\hline 19 & I & I & I & I & I & C & C & C & C & C & C & C & I & I & I & I & I & I & I & I & I \\
\hline 20 & I & I & I & I & I & C & C & C & $\mathrm{C}$ & C & C & C & I & I & I & I & I & I & I & I & I \\
\hline 21 & C & C & C & C & C & I & I & I & I & I & I & I & I & I & I & I & I & I & I & I & I \\
\hline
\end{tabular}

Cross 2

\begin{tabular}{|c|c|c|c|c|c|c|c|c|c|c|c|c|c|c|c|c|c|c|c|c|}
\hline \multirow{2}{*}{${ }^{\circ}$} & \multicolumn{2}{|c|}{ A } & \multicolumn{6}{|c|}{ B } & \multicolumn{5}{|c|}{ C } & \multicolumn{7}{|c|}{ D } \\
\hline & 1 & 2 & 3 & 4 & 5 & 6 & 7 & 8 & 9 & 10 & 11 & 12 & 13 & 14 & 15 & 16 & 17 & 18 & 19 & 20 \\
\hline 1 & I & I & I & I & 1 & I & I & I & I & I & I & I & I & C & C & C & C & C & C & C \\
\hline 2 & I & I & I & 1 & I & I & I & I & I & I & I & I & I & C & C & C & C & C & C & C \\
\hline 3 & I & I & I & I & I & I & I & I & C & C & C & C & C & C & C & C & C & C & C & C \\
\hline 4 & I & I & I & I & I & I & I & I & C & C & C & C & C & C & C & C & C & C & C & C \\
\hline 5 & I & I & I & I & I & I & I & I & C & C & C & C & C & C & C & C & C & C & C & C \\
\hline 6 & I & I & 1 & I & I & I & I & I & C & C & C & C & C & C & C & C & C & C & C & C \\
\hline 7 & I & I & I & I & I & I & I & I & C & C & C & C & C & C & C & C & C & C & C & C \\
\hline 8 & I & I & I & I & 1 & I & I & I & C & C & C & $\mathrm{C}$ & C & C & C & C & C & C & C & C \\
\hline 9 & I & I & C & C & C & C & C & C & I & I & I & I & I & $I^{*}$ & $I^{*}$ & $I^{*}$ & $I^{*}$ & I* & I & $I^{*}$ \\
\hline 10 & I & I & C & C & C & C & C & C & I & I & I & I & I & $\mathrm{I}^{*}$ & I & I & I & $\mathrm{I}^{*}$ & I & $\mathrm{I}^{*}$ \\
\hline 11 & I & I & C & C & C & C & C & C & I & I & I & I & I & $\mathrm{I}^{*}$ & I & $I^{*}$ & $I^{*}$ & $\mathrm{I}^{*}$ & I & $\mathrm{I}^{*}$ \\
\hline 12 & I & I & C & C & C & C & C & C & I & I & I & I & I & $I^{*}$ & I* & $I^{*}$ & I & $\mathrm{I}^{*}$ & I & I \\
\hline 13 & I & I & C & C & C & C & C & C & I & I & I & I & I & I & $I^{*}$ & I & I & I* & $\mathrm{I}^{*}$ & $I^{*}$ \\
\hline 14 & C & C & C & C & C & C & C & C & I & I & I & I & I & $I^{*}$ & $I^{*}$ & I & $I^{*}$ & I & I & $\mathrm{I}^{*}$ \\
\hline 15 & C & C & C & C & C & C & C & C & I & I & I & I & I & $I^{*}$ & I & $I^{*}$ & I & I & I & $I^{*}$ \\
\hline 16 & C & C & C & C & C & C & C & C & I & I & I & I & I & $I^{*}$ & $I^{*}$ & I & I & I* & $I^{*}$ & $\mathrm{I}^{*}$ \\
\hline 17 & C & C & C & C & C & C & C & C & I & I & I & I & I & $\mathrm{I}^{*}$ & I & $\mathrm{I}^{*}$ & $I^{*}$ & $\mathrm{I}^{*}$ & I & $\mathrm{I}^{*}$ \\
\hline 18 & C & C & C & C & C & C & C & C & I & I & I & I & I & $I^{*}$ & I & $\mathrm{I}^{*}$ & I & I* $^{*}$ & I & 1 \\
\hline 19 & C & C & C & C & C & C & C & C & I & I & I & I & I & $\mathrm{I}^{*}$ & I & I & I & I & I & $I^{*}$ \\
\hline 20 & C & C & C & C & C & C & C & C & I & I & I & I & I & $I^{*}$ & $\mathrm{I}^{*}$ & $\mathrm{I}^{*}$ & I & $\mathrm{I}^{*}$ & I & I \\
\hline
\end{tabular}

Figure 2 Results of diallel crosses for $F_{1}$ families from cross 1 (top) and cross 2 (bottom). $C=$ compatible, $I=$ incompatible, $I^{*}=$ leaky incompatible (see text). The $S$-allele genotypes of the incompatibility groups in cross 1 are $A=S_{20 \cdot 32}, B=S_{32 \cdot 36}, C=$ $\mathrm{S}_{20.38}, \mathrm{D}=\mathrm{S}_{36 \cdot 38} ;$ and in cross $2, \mathrm{~A}=\mathrm{S}_{23 \cdot 37} ; \mathrm{B}=\mathrm{S}_{20 \cdot 23}, \mathrm{C}=\mathrm{S}_{13 \cdot 37}, \mathrm{D}=\mathrm{S}_{13 \cdot 20}$. 
Cross 1

\begin{tabular}{|c|c|c|c|c|c|c|c|c|c|c|c|c|c|c|c|c|c|c|c|c|}
\hline 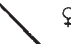 & \multicolumn{2}{|c|}{ A } & \multicolumn{4}{|c|}{ B } & \multicolumn{14}{|c|}{ C } \\
\hline to & 1 & 2 & 3 & 4 & 5 & 6 & 7 & 8 & 9 & 10 & 11 & 12 & 13 & 14 & 15 & 16 & 17 & 18 & 19 & 20 \\
\hline 1 & 1 & 1 & $C$ & C & C & C & & I & I & I & & & & & I & I & I & & I & \\
\hline 2 & I & I & C & C & C & C & I & I & I & I & I & I & I & I & I & I & I & I & I & I \\
\hline 3 & C & C & I & & I & I & & I & I & 1 & & I & I & I & I & 1 & I & & I & I \\
\hline 4 & C & C & I & I & I & I & I & I & I & 1 & 1 & 1 & I & I & I & I & I & 1 & I & I \\
\hline 5 & C & C & & I & I & I & 1 & I & I & I & I & I & I & 1 & I & I & I & I & I & I \\
\hline 6 & C & C & I & 1 & I & I & I & I & I & I & I & I & I & I & I & I & I & I & I & I \\
\hline 7 & I & I & I & I & & I & I & I & I & I & I & I & I & & I & I & I & I & I & 1 \\
\hline 8 & & I & & I & & I & I & I & I & I & I & & I & & I & I & I & & I & \\
\hline 9 & & I & & I & I & I & & I & 1 & 1 & & & & & I & I & I & & I & \\
\hline 10 & I & I & I & I & I & I & 1 & I & I & I & I & I & I & I & I & I & I & I & I & I \\
\hline 11 & I & I & I & I & I & I & & I & I & I & I & I & I & & I & I & I & I & I & I \\
\hline 12 & I & I & & & I & I & & I & I & I & I & I & I & & I & I & I & & I & \\
\hline 13 & I & I & I & I & I & I & & & I & 1 & & & I & I & I & I & I & & I & \\
\hline 14 & I & I & & I & I & I & 1 & I & I & I & I & I & I & 1 & I & I & I & I & I & I \\
\hline 15 & I & I & I & I & I & I & I & I & I & I & I & I & I & I & I & I & I & I & I & I \\
\hline 16 & I & I & I & I & I & I & I & I & I & 1 & I & I & I & I & I & I & I & I & I & I \\
\hline 17 & I & I & I & I & I & I & I & I & I & I & I & I & I & I & I & I & I & I & I & I \\
\hline 18 & I & I & I & I & & I & & I & I & I & & I & I & & I & I & I & I & I & I \\
\hline 19 & I & I & I & I & I & I & I & I & I & I & I & I & I & I & I & I & I & I & I & I \\
\hline 20 & I & I & I & I & I & I & & I & I & I & & I & I & & I & I & I & & I & I \\
\hline
\end{tabular}

Cross 2

\begin{tabular}{|c|c|c|c|c|c|c|c|c|c|c|c|c|c|c|c|c|c|c|c|c|}
\hline 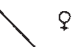 & \multicolumn{4}{|c|}{ A } & \multicolumn{6}{|c|}{ B } & \multicolumn{10}{|c|}{ C } \\
\hline$\delta$ & 1 & 2 & 3 & 4 & 5 & 6 & 7 & 8 & 9 & 10 & 11 & 12 & 13 & 14 & 15 & 16 & 17 & 18 & 19 & 20 \\
\hline 1 & 1 & I & I & I & C & C & C & C & C & C & C & C & C & C & C & C & C & C & C & C \\
\hline 2 & 1 & I & I & I & C & C & C & C & C & C & C & C & C & C & C & C & C & C & C & C \\
\hline 3 & I & I & I & C & C & C & C & C & C & C & C & C & C & C & C & C & C & C & C & C \\
\hline 4 & I & I & I & I & C & C & C & C & C & C & C & C & C & C & C & C & C & C & C & C \\
\hline 5 & C & & C & C & I & I & I & 1 & & I & I & I & I & I & I & I & I & I & & I \\
\hline 6 & C & C & C & C & 1 & I & & & & I & 1 & I & I & I & I & I & I & & & I \\
\hline 7 & C & & C & C & I & 1 & I & I & & 1 & I & I & 1 & I & I & I & I & I & I & 1 \\
\hline 8 & C & C & C & C & I & I & & 1 & & I & I & 1 & I & I & I & I & I & I & I & I \\
\hline 9 & C & C & & C & 1 & 1 & I & I & I & 1 & I & I & I & I & I & 1 & I & I & I & I \\
\hline 10 & C & C & C & C & I & I & 1 & 1 & 1 & I & 1 & I & I & 1 & I & I & I & I & I & I \\
\hline 11 & I & I & I & 1 & I & I & I & 1 & I & I & I & I & I & I & I & 1 & I & I & l & I \\
\hline 12 & I & & I & I & 1 & 1 & I & 1 & & I & 1 & I & I & I & 1 & 1 & & & I & \\
\hline 13 & I & I & I & 1 & I & 1 & I & & & I & 1 & & I & & I & I & 1 & I & & 1 \\
\hline 14 & 1 & & I & & I & & & & & I & 1 & I & I & 1 & I & I & I & & & I \\
\hline 15 & I & I & & I & & & & & & & I & & I & & I & I & I & & & \\
\hline 16 & I & I & I & I & & I & & I & I & & I & 1 & I & & I & I & 1 & & & 1 \\
\hline 17 & I & I & 1 & I & I & I & I & I & 1 & I & I & I & I & I & I & I & I & I & I & I \\
\hline 18 & I & I & I & I & I & I & & & & I & I & I & I & I & I & I & I & I & & I \\
\hline 19 & 1 & 1 & I & I & & I & & & & I & I & I & I & I & I & I & I & I & I & I \\
\hline 20 & 1 & I & I & 1 & I & & & & & I & I & I & & & & I & I & & & I \\
\hline
\end{tabular}

Figure 3 Results of diallel crosses for $F_{2}$ families from cross 1 (top) and cross 2 (bottom). $C=$ compatible, $I=$ incompatible. The $S$ allele genotypes of the incompatibility groups in cross 1 are $A=S_{38 \cdot 38}, B=S_{20 \cdot 20}, C=S_{20 \cdot 38}$; and in cross $2, A=S_{20 \cdot 20}, B=$ $\mathrm{S}_{23 \cdot 23}, \mathrm{C}=\mathrm{S}_{20 \cdot 23}$. 
(Although Verma et al. (loc. cit.) checked some incompatible reactions cytologically, no compatible reactions were tested in this way.) Sampson (1964) noted an association between the technique used in determining compatibility reactions and the conclusions reached in studies of the number of S-loci in $R$. sativus and $R$. raphanistrum, authors using the seed-set technique concluding that two or more loci were involved, whereas those using cytological techniques concluded that only one locus was involved. The more recent claim by Lewis (1979) that a one gene system is "definitely excluded" in $R$. sativus has not yet, to our knowledge, been supported by any published data. Therefore, before E. sativa is adopted as an exception to the general rule that sporophytic selfincompatibility systems are under single-locus control, it would be desirable to repeat the study using fluorescence microscopy to score all compatibility reactions cytologically.

A final point concerns the leakiness observed in some of our incompatible reactions. It is well known that factors other than the precise specificity of an S-allele may modify its expression resulting in incomplete dominance (Sampson, 1964; HoserKrauze, 1971; Thompson, 1972; Wallace, 1979a), or mutual or independent weakening (Thompson, 1972; Mackay, 1977; Ockendon and Currah, 1979; Wallace, 1979a; Visser et al., 1982). The leakiness observed in the self family of WF184 apparently provides an example of incomplete dominance, while that observed in the $F_{1}$ family of cross 2 apparently demonstrates mutual weakening of $\mathrm{S}$ allele activities in the stigma.

Acknowledgements We are indebted to $\mathrm{Dr}$ M. A. Ford for initiating the $S$-allele seed collection (for $S_{1}$ to $S_{14}$ ), and for collecting the seed samples from the South Wales and Lincolnshire populations. We thank Drs D. P. Stevens and M. A. Ford for their constructive discussion throughout the project. The financial assistance of the N.E.R.C. is gratefully acknowledged.

\section{REFERENCES}

BAteman, A. J. 1954. Self-incompatibility systems in Angiosperms. II. Iberis amara. Heredity, 8, 305-332.

BAtEMAN, A. J. 1955. Self-incompatibility systems in Angiosperms. III. Cruciferae. Heredity, 9, 53-68.

CROWE, L. 1954. Incompatibility in Cosmos bipinnatus. Heredity, 8, 1-11.

CORNISH, M. A., HAYWARD, M. D. AND LAWRENCE, M. J. 1979. Self-incompatibility in ryegrass. I. Genetic control in diploid Lolium perenne L. Heredity, 43, 95-106.

EENINK, A. H. 1981. Compatibility and incompatibility in witloof-chicory (Cichorium intybus L.). II. The incompatibility system. Euphytica, 30, 77-85.
FORD, M. A. 1986. Pollinator-mediated interactions between outbreeding annual weeds. Ph.D. Thesis, University of Wales.

FORD, M. A. AND KAY Q. O. N. 1985. The genetics of incompatibility in Sinapis arvensis L. Heredity, 54, 99-102.

GERSTEL, D. U. 1950. Self-incompatibility studies in Guayale. II. Inheritance. Genetics, 35, 482-506.

HOSER-KRAUZE, J. 1971. Inheritance of self-incompatibility in several early cabbage varieties (Brassica oleracea var. capitata f. alba). Genet. Polon., 12, 37-49.

HUGHES, M. B. AND BABCOCK, E. B. 1950. Self-incompatibility in Crepis foetida (L.) subsp. rhoeadifolia (Bieb.) Schinz et Keller. Genetics, 35, 570-588.

IMRIE, B. C. AND KNOWLES, P. F. 1971. Genetic studies of self-incompatibility in Carthamus flavescens Spreng. Crop Sci., 11, 6-9.

KHO, Y. O. AND BAËR, J. 1968. Observing pollen tubes by means of fluorescence. Euphytica, 17, 298-302.

LAWRENCE, M. J., AFZAL, M. AND KENRICK, J. 1978. The genetical control of self-incompatibility in Papaver rhoeas. Heredity, 40, 239-253.

LEWIS, D. 1977. Sporophytic incompatibility with two and three genes. Proc. R. Soc. Lond. B, 196, 161-170.

LEWIS, D. 1979. Genetic versatility of incompatibility in plants. New Zealand J. Bot., 17, 637-644.

LLOYD, D. G. 1967. The genetics of self-incompatibility in Leavenworthia crassa Rollins (Cruciferae). Genetica, 38, 227-242.

MACKAY, G. R. 1977. A diallel cross method for he recognition of S-allele homozygotes in turnip, Bras' : a campestris L. ssp. rapifera. Heredity, 38, 201-208.

OCKENDON, D. J. 1980. Distribution of S-alleles and breeding structure of Cape broccoli (Brassica oleracea var. 'italica'). Theor. appl. Genet., 58, 11-15.

OCKENDON, D. J. AND CURRAH, L. 1979. Breeding structure of a highly selected cultivar of cabbage (Brassica oleracea var. capitata). Heredity, 42, 373-379.

ØSTERBYE, U. 1986. Self-incompatibility in Ranunculus acris L. III. S-loci numbers and allelic identities. Hereditas, 104, 61-73.

RICHARDS, R. A. AND THURLING, N. 1973. The genetics of self-incompatibility in Brassica campestris ssp. oleifera Metzg. I. Characteristics of S-locus. Control of self-incompatibility. Genetica, 44, 428-438.

SAMPSON, D. R. 1957a. The genetics of self- and crossincompatibility in Brassica oleracea. Genetics, 42, 253263.

SAMPSON, D. R. $1957 \mathrm{~b}$. The genetics of incompatibility in radish. J. Hered., 48, 26-29.

SAMPSON, D. R. 1958. The genetics of self-incompatibility in Lesquerella densipila and in the $\mathrm{F}_{1}$ hybrid $L$. densipila $\times L$. lescurii. Can. J. Bot., 36, 39-56.

SAMPSON, D. R. 1964. A one-locus self-incompatibility system in Raphanus raphanistrum. Can. J. Bot., 6, 435-445.

STEPHENS, L. C., ASCHER, P. D. AND WIDMER, R. E. 1982. Genetics of self-incompatibility in diploid Ageratum houstonianum Mill. Theor. Appl. Genet., 63, 287-394.

THOMPSON, K. F. 1957. Self-incompatibility in marrow-stem kale, Brassica oleracea var. acephala. I. Demonstration of a sporophytic system. J. Genet., 55, 45-60.

THOMPSON, K. F. 1972. Competitive interaction between two S-alleles in a sporophytically-controlled incompatibility system. Heredity, 28, 1-7.

VERMA, S. C., MALIK, R. AND DHIR, I. 1977. Genetics of the incompatibility system in the crucifer Eruca sativa L. Proc. R. Soc. B, 196, 131-159. 
VISSER, D. L., VAN HAL, J. G. AND VERHOEVEN, W. H. 1982. Classification of S-alleles by their activity in Sheterozygotes of Brussels sprouts (Brassica oleracea var. gemmifera (DC.) Schultz). Euphytica, 31, 603-611.

WALLACE, D. H. 1979 $a$. Interactions of S-alleles in sporophytically controlled self incompatibility of Brassica. Theor. Appl. Genet., 54, 193-201. wallace, D. H. $1979 \mathrm{~b}$. Procedures for identifying S-allele genotypes of Brassica. Theor. Appl. Genet., 54, 249-265.

ZUBERI, M. I., ZUBERI, S. AND LEWIS, D. 1981. The genetics of incompatibility in Brassica. I. Inheritance of selfcompatibility in Brassica campestris L. var. Toria. Heredity, 46, 175-190. 